\title{
Single cutaneous metastasis of colon adenocarcinoma - Case report ${ }^{*}$
}

\author{
Heliana Freitas de Oliveira Góes ${ }^{1}$ \\ Mariana Boechat de Souza ${ }^{1}$ \\ Mônica Ali Novaes Faria ${ }^{1}$
}

\author{
Caren dos Santos Lima ${ }^{1}$ \\ Rogério Ribeiro Estrella ${ }^{1}$ \\ Mayra Carrijo Rochael ${ }^{1}$
}

DOI: http:/ / dx.doi.org/10.1590/abd1806-4841.20164122

\begin{abstract}
Skin metastases are relatively rare and occur most often when the cancer is already advanced, invading other organs. As to location, they often seem to elect areas located close to the primary tumor, although distant sites, such as the scalp, may be affected with some frequency. We present a case of a 76-year-old woman with colon adenocarcinoma that had a single metastatic lesion on the scalp.
\end{abstract}

Keywords: Adenocarcinoma; Neoplastic metastasis; Skin neoplasms

\section{INTRODUCTION}

Metastases represent one of the most outstanding characteristics of malignant neoplasms and are relatively rare in the skin, in spite of the great extension of the cutaneous organ. ${ }^{1}$ They occur from $0.7 \%$ to $5 \%$ of patients with cancer. In those with metastatic disease, this rate is up to $10.4 \% .^{2}$ Cutaneous metastases generally represent a late event in the course of an advanced internal malignancy with involvement of other organs, However, frequently it can be the first signal of malignancy, which occurs with greater frequency in lung carcinoma, followed by kidney and ovary cancer. ${ }^{1}$

Of all tumors, breast cancer most commonly spreads as cutaneous metastasis by direct, hematogenic, and lymphatic pathways por spreading, with incidence of $24 \%$ according to a meta-analysis by Krathen et al. ${ }^{2}$ Lung, colorectal, renal, ovarian and bladder cancer have similar rates of cutaneous metastases, which vary from $3.4 \%$ to $4 \%$, mainly through blood and lymphatic dissemination. ${ }^{3}$
As to location, cutaneous metastases often favor areas close to the primary malignancy, such as lung cancer and skin metastases on the trunk. However, remote sites as the scalp may be also involved. ${ }^{1}$

We present the case of a 76-year-old patient with colon cancer and a single metastatic lesion on the scalp.

\section{CASE REPORT}

A 76-year-old female patient, with a descending colon cancer, presented an asymptomatic nodule on the scalp that had been present for two months, along with a veico-colonic fistula. Physical examination showed an emaciated and bedridden patient with a firm, $3 \mathrm{~cm}$, skin-colored, well-delimitated nodule, with lobulated surface, located in the left parietal region (Figure 1). CT of skull demonstrated that the lesion was restricted to the subcutaneous tissue, without communication with the cranial bone. No metastases

Received on 16.10.2014.

Approved by the Advisory Board and accepted for publication on 05.01.2015.

Worked performed at Hospital Universitário Antônio Pedro, Universidade Federal Fluminense (HUAP-UFF) - Niterói (RJ), Brazil. Financial Support: None. Conflict of Interest: None.

1 Universidade Federal Fluminense (UFF) - Niterói (RJ), Brazil. 
were detected in $\mathrm{CT}$ of the trhorax, abdomen, and pelvis. Excisional biopsy of the scalp lesion was performed, and the histopathological examination revealed mucin-secreting adenocarcinoma as cutaneous metastasis (Figures 2 and 3). The patient then underwent transversectomy, segmental enterectomy, partial cystostomy, end-to-end anastomosis, double-barrel colostomy and bladder suture in two planes. Anatomopathological examination of the surgical specimen

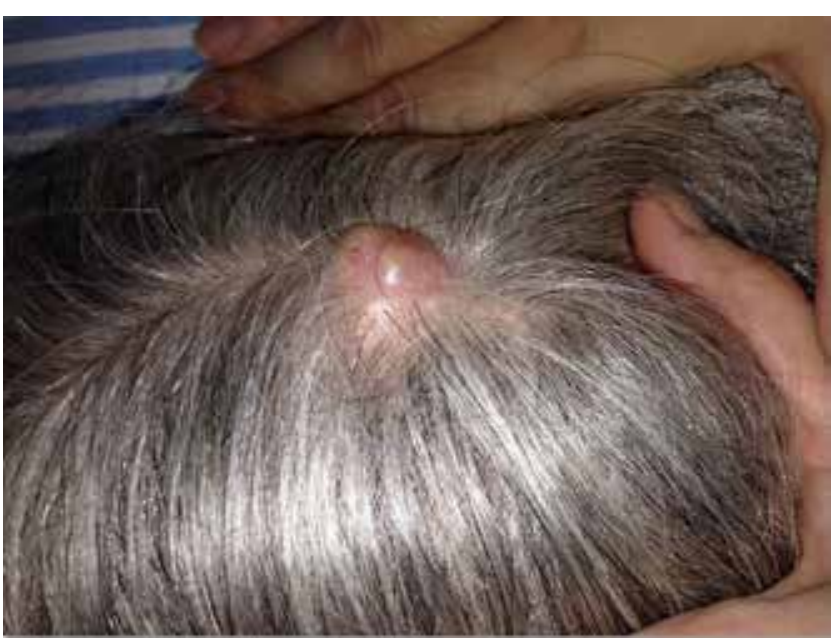

FigURE 1: Skin-colored, well-delimitated nodule of approximately 3 $\mathrm{cm}$ in diameter, with lobulated surface and firm consistence, located in the left parietal region demonstrated moderately differentiated adenocarcinoma of the descending colon, staging pT4b Pn0. Enlargement of the surgical margins of the scalp lesion was perfomed, and chemotherapy FOLFOX scheme (5-fluorouracil, leucovorin, and oxaliplatin) was instituted. The patient has remained stable clicaly stable.

\section{DISCUSSION}

Cutaneous metastasis of colorectal adenocarcinoma a rare event $(2.3 \%$ to $6 \%)$ that usually occur two years after the detection or resection of the primary tumor. ${ }^{4,5}$ It seldom occurs before the identification of the primary tumor and involvement of secondary organs, such as the liver. There are few cases, like ours, reported with only cutaneous metastases. ${ }^{6,7}$

The most frequent cutaneous site of colon cancer metastasis is is the surgical scar in the abdomen that results from the removal of the malignancy. The metastasis may also occur in preexistent non-related surgical scars, but there are few cases reported. ${ }^{8} \mathrm{Um}$ bilical metastasis ("Sister Mary Joseph nodule") may be a frequent finding. Other cutaneous sites, in descending order of frequency, are: pelvis, back, thorax, extremities, head and neck. ${ }^{9}$ In this report, the patient presented a single metastatic lesion located in the scalp, probably through blood or lymphatic dissemination.

Clinical presentation of cutaneous metastases is quite variable. Lesions may be single or multiple, violaceous or skin-colored, hard or soft, may mimic epidermal cysts, neurofibromas, lipomas or morphea, and may cause alopecia. More rarely, it may simulate infection, which is called inflammatory metastatic carcinoma or
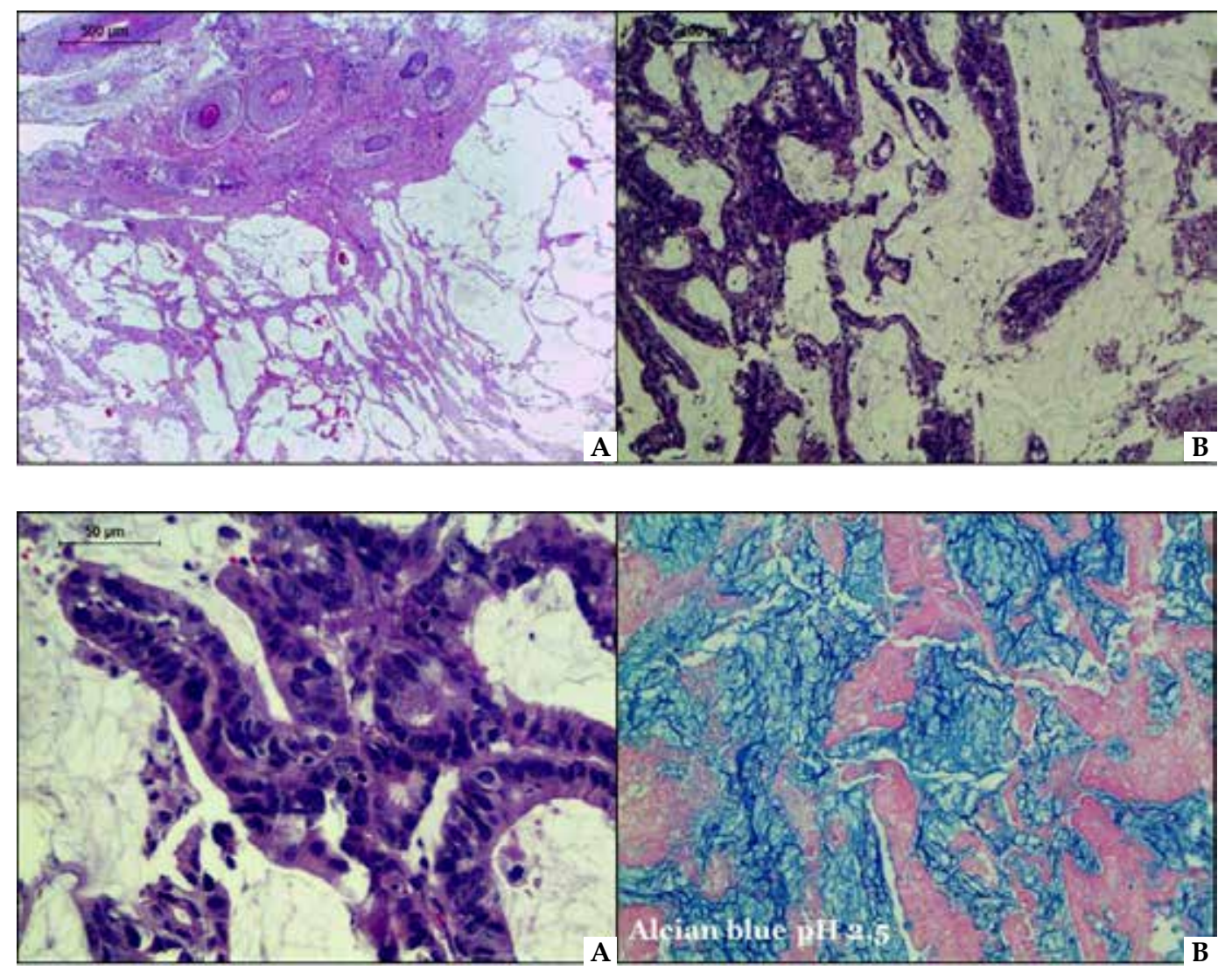

Figure 2: Fragment of the scalp. A. Hair follicles associated with cell proliferation forming septa with mucinous content (HE, 40x) B. Area of greater cellularity, with arrangement resembling glands (HE, 40x)

Figure 3: Fragment of the scalp. A. Atypical cells, presenting hyperchromatic nuclei with unequivocal nucleolus, and caliciform cells (HE, 40x) B. Alcian blue $(\mathrm{pH}$ 2.5) staining demonstrates production of mucin by the neoplasm (40x) 
erysipeloid carcinoma. At the histological examination, the identification of the primary tumor is not always possible by the usual methods, because metastases are frequently more anaplastic., ${ }^{2,9}$

The majority of metastases are well diferentiated, mucin-secreting adenocarcinomas. They usually have a nodular configuration and are located in the dermis, with subsequent infiltration of epidermis and the subcutaneous cell tissue. ${ }^{9}$

Survival after cutaneous metastasis diagnosis varies from one to 34 months. The average survival of patients after the diagnosis of cutaneous metastasis of colon carcinoma is 18 months. ${ }^{9}$

Single cutaneous metasis by be surgically removed. For extensive cutaneous metastases, the treatment is only palliative, for they are linked to significantly higher rates of distant metastases and uncontrolled local disease, as well as lower survival rates. ${ }^{10}$ There are no guidelines for the ideal chemotherapy regimen. since they are associated to 5-fluorouracil, capecitabine, irinotecan, oxaliplatin and cisplatin. ${ }^{9}$

\section{REFERENCES}

1. Rochael MC, Estrella RR. Metástases Cutâneas. In: Neves RG; Lupi 0, orgs. Câncer da Pele. Rio de Janeiro: MEDSI; 2001. p. 393-405.

2. Krathen RA, Orengo IF, Rosen T. Cutaneous metastasis: A meta-analysis of data. South Med J. 2003;96:164-7.

3. Hu SC, Chen GS, Wu CS, Chai CY, Chen WT, Lan CC. Rates of cutaneous metástases from different internal malignancies: Experience from a Taiwanese medical center. J Am Acad Dermatol. 2009;60:379-87.

4. Reilly WT, Nelson H, Schroeder G, Wieand HS, Bolton J, O'Connell MJ. Wound recurrence following conventional treatment for colorectal cancer: A rare but perhaps underestimated problem. Dis Colon Rectum. 1996;39:200-7.

5. Saeed S, Keehn CA, Morgan MB. Cutaneous metastasis: A clinical, pathological, and immunohistochemical appraisal. J Cutan Pathol. 2004;31:419-30.

6. Camci C, Türk HM, Büyükberber S, Karakök M, Koruk M, Beyazity Y, et al. Colon carcinoma with synchronous subcutaneous and osseous metastasis: A case report. J Dermatol. 2002;29:362-5.

7. Wright PK, Jha MK, Barrett PD, Bain IM. Colonic Adenocarcinoma Presenting as a Cutaneous Metastasis in an Old Operative Scar. J Postgrad Med. 2003;49:157-8.

8. Gupta SS, Singh 0. Carcinoma colon presenting as cutaneous metastasis to an old operative scar of hysterectomy. J Cancer Res Ther. 2010;6:316-7.

9. Nesseris I, Tsamakis C, Gregoriou S, Ditsos I, Christofidou E, Rigopoulos D. Cutaneous metastasis of colon adenocarcinoma: case report and review of the literature. An Bras Dermatol. 2013;88:56-8.

10. Gu Y, Tang R, Gong DQ, Qian YL. Reconstruction of the abdominal wall by using a combination of the human acellular dermal matrix implant and an interpositional omentum flap after extensive tumor resection in patients with abdominal wall neoplasm: a preliminary result. World J Gastroenterol. 2008;14:752-7.
In conclusion, dermatological evaluation of patients who are undergoing screening or who have already been diagnosed with cancer is extremely important, for it provides a high level of suspicion with the onset of cutaneous lesions, even if these are clinically compatible with benign illnesses - as the example of the present case, in which the cutaneous metastasis was single and mimicked an epidermal cyst. This evaluation also helps with the therapy, because most of the times, cutaneous metastases already indicate a worse prognostic of a neoplastic disease.]

\author{
MAILING ADDRESS: \\ Heliana Freitas de Oliveira Góes \\ Rua Itararé, 177, apto 96 - Bela Vista \\ 01308030 - São Paulo - SP \\ Brazil \\ E-mail: heliana_g@yahoo.com.br
} How to cite this article: Góes HFO, Lima CS, Souza MB, Estrella RR, Faria MAN, Rochael MC. Single cutaneous
metastasis of colon adenocarcinoma - Case report.. An Bras Dermatol. 2016;91(4):517-9. 